\title{
Mechanism for Loss of Hot Ductility Due to Deformation during Solidification in Continuous Casting of Steel
}

\author{
Faramarz ZARANDI and Steve YUE
}

Department of Metals and Materials Engineering, McGill University, M.H. Wong Building, 3610 University, Montreal, QC H3A 2B2, Canada. E-mail: faramarz.zarandi@mail.mcgill.ca, steve.yue@mcgill.ca

(Received on April 5, 2004; accepted in final form on July 5,2004)

\begin{abstract}
Strand surface cracking is a problem that can lead to scrap the product of the continuous casting process. Stress and strain developed during continuous casting have been found to be effective in this respect. The crack susceptibility is usually evaluated by assessing the steel hot ductility at the straightening stage of the process. The hot ductility of two Nb-microalloyed steels was evaluated in in situ melted specimens. The billet surface thermal history was simulated in order to generate the billet surface microstructure. The effect of deformation incorporated with steel solidification was studied and it was found that any kind of deformation during solidification results in loss of hot ductility. Metallography of specimens revealed that deformation caused grain boundary cracking and changed the segregation pattern, leading to loss of hot ductility. Based on this, a mechanism for hot ductility loss was proposed.
\end{abstract}

KEY WORDS: continuous casting; hot ductility; thermal schedule; deformation; segregation; fractography; microstructure.

\section{Introduction}

Since the advent of continuous casting process of steel, the industry has been facing with the problem of cracking on the surface of billet/slab. These cracks are present along oscillation marks, on the mid-face, and at the corners of cast slabs. In general, surface cracks in the continuous casting can be classified in two categories; cracks which occur during solidification and those which occur after solidification of the steel skin. Stresses developed during the process are the main cause in both cases.

Molten steel is poured from a ladle via a tundish into an oscillating, water-cooled copper mould, which is often curved. The mould oscillates to prevent welding or sticking of the cast metal to the mould, and consequent high apparent friction and tearing of the solidifying skin. However, some friction occurs at the interface of the mould and solidified skin, resulting in stresses in the skin. ${ }^{1)}$ Basically, the resultant stress and strain are the sum of the bending and axial components. Provided these stress and strain are sufficiently high, failure of the skin and a breakout can occur, leading to cracking. These cracks can grow during subsequent deformations owing to thermal gradients, ${ }^{2)}$ ferrostatic pressure of liquid, and rolls misalignment, ${ }^{1)}$ which results in defected products. In addition to the cracking in the mould, there is also a problem of cracking during straightening of billet at the end of the continuous casting process. This is associated with low hot ductility in steel, especially microalloyed steels. ${ }^{3)}$

Many investigations have been done to resolve the problem of cracking and hot ductility. As for cracking in the mould, there have been numerous reports during last two decades about improvement in slab surface quality by technologies which do not depend on mould oscillation, such as molten steel flow control in the mould and electromagnetic force imposed on the meniscus. ${ }^{4-8)}$ Also, there are some valuable work concerning alloying elements. ${ }^{9)}$ In a new approach, effect of deformation on the hot ductility in in-situ melted specimens was studied. ${ }^{10)}$ From the results of that work, it was suggested that compression incorporated with solidification could improve the hot ductility by closing solidification voids and shrinkages and tension could deteriorate it by expanding these discontinuities. Even though this seems plausible from one side, it does not conform to what was explained above about the effect of deformation in the mould. Hence, the purpose of this work is to investigate the effect of deformation during solidification of steel with regard to the hot ductility at the straightening stage.

\section{Experiments}

Two grades of microalloyed steels; $\mathrm{Nb}-\mathrm{Ti}-\mathrm{B}$ and $\mathrm{Nb}-\mathrm{Ti}$, were chosen. The chemistries are given in Table 1. The principal difference between these grades is that the former has high hot ductility but the latter has a severe hot ductility problem. Therefore, using these steels, the effect of deformation during solidification on the hot ductility can be studied more effectively. Cylindrical specimens of $9.5 \mathrm{~mm}$ in diameter and $125 \mathrm{~mm}$ in length were machined from the steel plates. In order to simulate the billet surface microstructure, two thermal schedules, which are typical of those of the mid-face surface of a $10^{\prime \prime} \times 10^{\prime \prime}$ billet in the con- 
Table 1. Chemical compositions of steels (wt $\%$ ).

\begin{tabular}{|c|c|c|}
\hline Elements & Nb-Ti-B & Nb-Ti \\
\hline $\mathrm{C}$ & 0.015 & 0.058 \\
\hline $\mathrm{Mn}$ & 1.650 & 1.210 \\
\hline $\mathrm{P}$ & 0.009 & 0.008 \\
\hline $\mathrm{S}$ & 0.008 & 0.011 \\
\hline $\mathrm{Si}$ & 0.230 & 0.159 \\
\hline $\mathrm{Nb}$ & 0.050 & 0.037 \\
\hline $\mathrm{Ti}$ & 0.020 & 0.017 \\
\hline $\mathrm{Al}$ & 0.020 & 0.020 \\
\hline $\mathrm{Cr}$ & 0.025 & 0.054 \\
\hline $\mathrm{Ni}$ & $<0.003$ & 0.111 \\
\hline $\mathrm{Mo}$ & $<0.017$ & 0.030 \\
\hline $\mathrm{V}$ & 0.002 & 0.002 \\
\hline $\mathrm{Co}$ & $<0.004$ & N/A \\
\hline $\mathrm{Sn}$ & $<0.001$ & 0.020 \\
\hline $\mathrm{Cu}$ & 0.001 & 0.462 \\
\hline $\mathrm{B}$ & $20 \mathrm{ppm}$ & N/A \\
\hline $\mathrm{N}$ & $48 \mathrm{ppm}$ & 0.0078 \\
\hline \multicolumn{3}{|c}{} \\
\hline
\end{tabular}

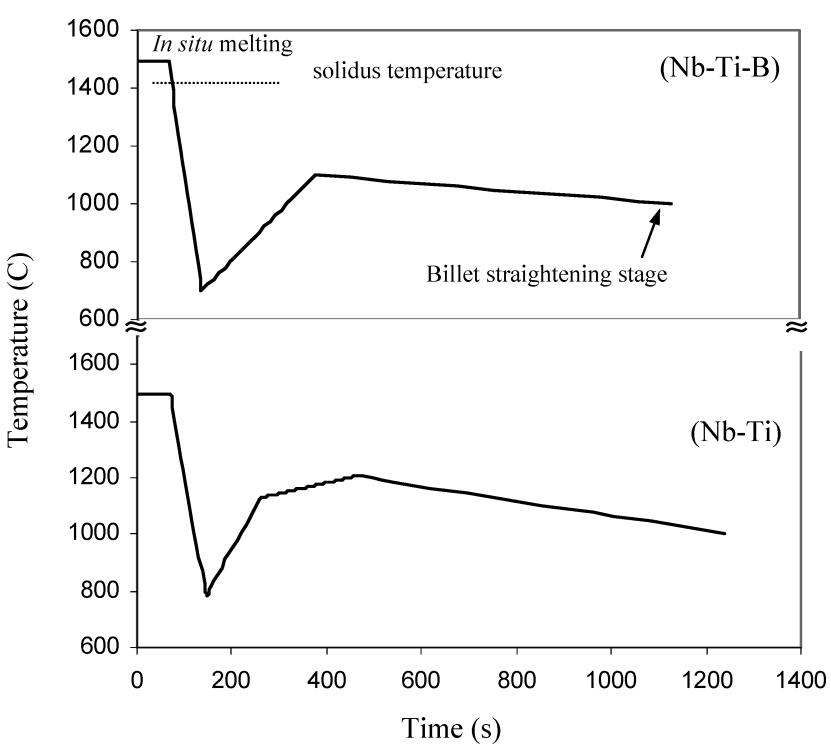

Fig. 1. Thermal schedules used to simulate the thermal condition of billet surface in the continuous casting process in the $\mathrm{Nb}-\mathrm{Ti}-\mathrm{B}$ steel and the $\mathrm{Nb}-\mathrm{Ti}$ steel. ${ }^{10,11)}$

tinuous casting process, ${ }^{10,11)}$ were selected, Fig. 1. The reason for this is because loss of hot ductility is associated with cracks occurring on the billet surface.

The thermal schedules were applied to specimens using an induction heating system. Specimens were heated in an atmosphere of argon containing $1 \%$ hydrogen in order to eliminate oxidation. Temperature was measured by an infrared pyrometer and regulated by a controller in accordance to the programmed thermal schedules.

Specimens were installed in a fully computerized MTS machine and fixed at both ends to provide a situation for applying both tension and compression on the same specimen. Then, they were heated and a gauge length of $\sim 20 \mathrm{~mm}$ was melted and solidified in-situ. The melted gauge length was held by levitation. Thermal expansion and contraction during heating and cooling were automatically compensated by displacement of the MTS anvil so that the load on specimens was maintained around zero, unless there was a deformation. Where the effect of deformation was to be studied, specimens were deformed for $\varepsilon=0.05$ or 0.1 at $\dot{\varepsilon}=9 \times 10^{-3} \mathrm{~s}^{-1}$ during solidification over

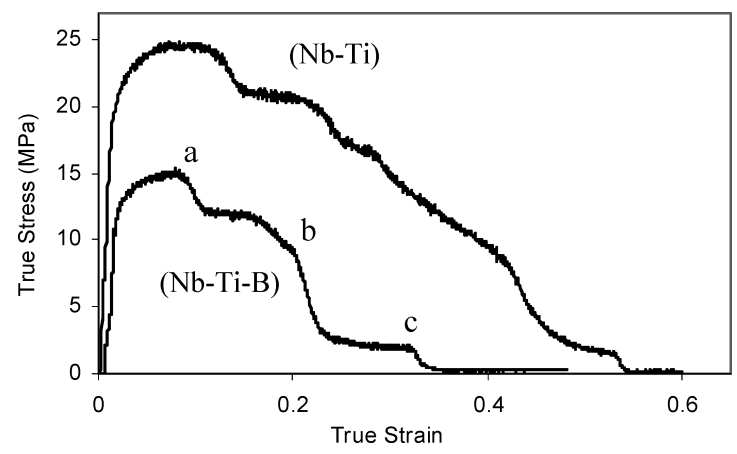

Fig. 2. Typical curves of the continuous heating tensile experiment. The tensile deformation was started at 1100 and $1200^{\circ} \mathrm{C}$ for the $\mathrm{Nb}-\mathrm{Ti}$ steel and the $\mathrm{Nb}-\mathrm{Ti}-\mathrm{B}$ steel, respectively $\left(\dot{\varepsilon}=3 \times 10^{-3} \mathrm{~s}^{-1}\right.$ and $\left.\dot{T}=2^{\circ} \mathrm{C} / \mathrm{s}\right)$.

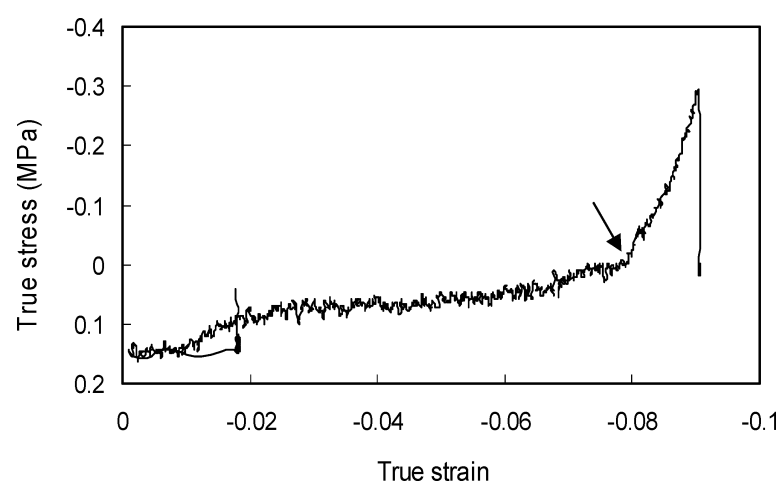

Fig. 3. Continuous cooling compression performed on a $\mathrm{Nb}-\mathrm{Ti}-\mathrm{B}$ specimen $\left(\dot{\varepsilon}=9 \times 10^{-3} \mathrm{~s}^{-1}\right.$ and $\left.\dot{T}=2^{\circ} \mathrm{C} / \mathrm{s}\right)$. The arrow indicates the solidus temperature on cooling.

the thermal schedules, i.e. the first segment of cooling in the thermal schedules proceeding at $10^{\circ} \mathrm{C} / \mathrm{s}$, Fig. 1 . Then, the hot ductility at the straightening stage of the thermal schedules was evaluated, Fig. 1, by performing a tensile test at $\dot{\varepsilon}=5 \times 10^{-3} \mathrm{~s}^{-1}$. This strain rate is similar to that experienced by the billet surface during the straightening operation in continuous casting. ${ }^{1)}$ Hot ductility was quantified by the reduction in area (RA) at fracture.

In order to determine the melting and solidus temperatures, two experiments, i.e. continuous heating tensile and continuous cooling compression, were performed. In the former, specimens were heated at $2^{\circ} \mathrm{C} / \mathrm{s}$ while being deformed at a rate of $\dot{\varepsilon}=3 \times 10^{-3} \mathrm{~s}^{-1}$. In the latter, specimens, after being melted, were cooled at a rate of $5^{\circ} \mathrm{C} / \mathrm{s}$ and simultaneously deformed in compression at $\dot{\varepsilon}=9 \times 10^{-3} \mathrm{~s}^{-1}$. The values for the deformation parameters were chosen according to the cooling rate and the thermal contraction of material. It was necessary that the specimen do not bulge out along the gauge length during compression since this would affect the slope of the load-displacement graph and lead to erroneous results.

Microstructural observation and fracture surface examination was performed using both optical and electron microscopes; JEOL T840 SEM and Field Emission Gun Hitachi-4700 SEM (FEGSEM).

\section{Results}

Figures $\mathbf{2}$ and $\mathbf{3}$ show typical stress/force-strain/displacement plots of the continuous heating/cooling tension/com- 


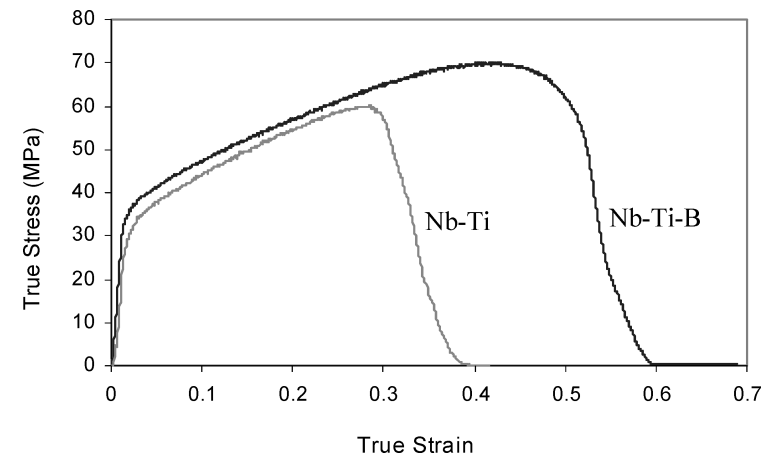

Fig. 4. Effect of the thermal schedules alone on mechanical behaviour of the steels at the straightening stage.

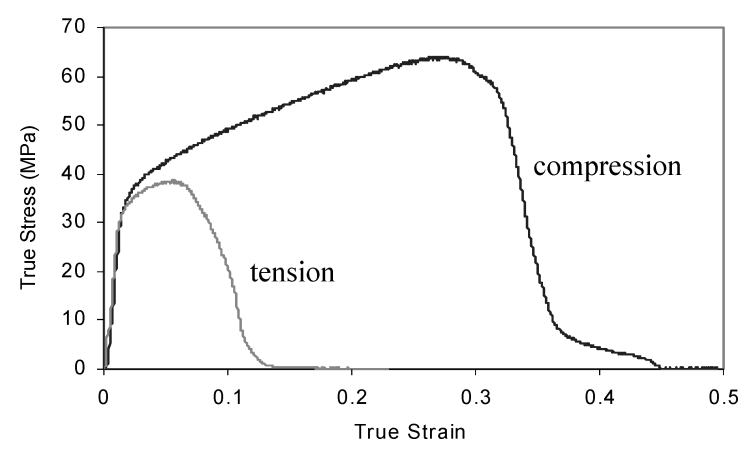

Fig. 5. Effect of tension and compression $(\varepsilon=0.05)$, during solidification, incorporated with the thermal schedule on mechanical behaviour of the $\mathrm{Nb}-\mathrm{Ti}-\mathrm{B}$ steel at the straightening stage.

pression experiments for both steels. There are three main drops in stress in Fig. 2. The first one, indicated by 'a', is attributed to dynamic recrystallization in austenite followed by dynamic transformation of austenite to delta-ferrite occurring at ' $b$ '. The last drop, indicated by ' $c$ ', occurs due to delta-ferrite grain boundary melting leading to zero strength of the material. This temperature is considered as the solidus temperature in heating. Also, by judiciously choosing right values for the strain rate and the cooling rate, the solidus temperature in cooling can be traced as it is shown in Fig. 3, where the strength of material suddenly increases. Note that the instantaneous temperature is proportional to the instantaneous displacement and can be determined with regard to the cooling rate and the deformation rate. In this way, solidus temperatures in cooling for the $\mathrm{Nb}-\mathrm{Ti}-\mathrm{B}$ and the $\mathrm{Nb}-\mathrm{Ti}$ steels were approximated to be 1425 and $1430^{\circ} \mathrm{C}$, respectively.

When the steels, after melting, were subjected to their respective thermal schedules alone, i.e. no deformation was incorporated, the $\mathrm{Nb}-\mathrm{Ti}-\mathrm{B}$ steel demonstrated an appreciable elongation at the straightening stage but the $\mathrm{Nb}$-Ti steel fractured much earlier, as shown in Fig. 4. The mechanical characteristics of both steels were deteriorated at the straightening stage when a deformation was incorporated with solidification. In this respect, tensile deformation appeared to be more detrimental than compressive deformation, Fig. 5.

The results of hot ductility evaluation are summarized in Table 2. Generally, the result shows that as long as there is a deformation during solidification, the hot ductility is markedly deteriorated.
Table 2. Effect of deformation start temperature on hot ductility.

\begin{tabular}{|c|c|c|}
\hline $\begin{array}{c}\text { Deformation } \\
\text { start } \\
\text { temperature }\end{array}$ & $\begin{array}{c}\text { Deformation } \\
\text { percentage } \\
\left(\dot{\varepsilon}=9 \times 10^{-3} \mathrm{~s}^{-1}\right)\end{array}$ & $\mathrm{RA} \%$ \\
\hline No deformation & No deformation & $\begin{array}{c}60 \text { (Nb-Ti-B) } \\
15 \quad(\mathrm{Nb}-\mathrm{Ti})\end{array}$ \\
\hline $\begin{array}{c}1490 \\
(\mathrm{Nb}-\mathrm{Ti}-\mathrm{B})\end{array}$ & $\begin{array}{c}5 \\
\text { (tension) }\end{array}$ & 4 \\
\hline $\begin{array}{c}1490 \\
(\mathrm{Nb}-\mathrm{Ti}-\mathrm{B})\end{array}$ & $\begin{array}{c}5 \\
\text { (compression) }\end{array}$ & 9 \\
\hline $\begin{array}{c}1481 \\
(\mathrm{Nb}-\mathrm{Ti})\end{array}$ & $\begin{array}{c}10 \\
\text { (compression) }\end{array}$ & 8 \\
\hline $\begin{array}{c}1462 \\
(\mathrm{Nb}-\mathrm{Ti})\end{array}$ & $\begin{array}{c}10 \\
\text { (compression) }\end{array}$ & 8 \\
\hline $\begin{array}{c}1440 \\
(\mathrm{Nb}-\mathrm{Ti})\end{array}$ & $\begin{array}{c}10 \\
\text { (compression) }\end{array}$ & 9 \\
\hline
\end{tabular}

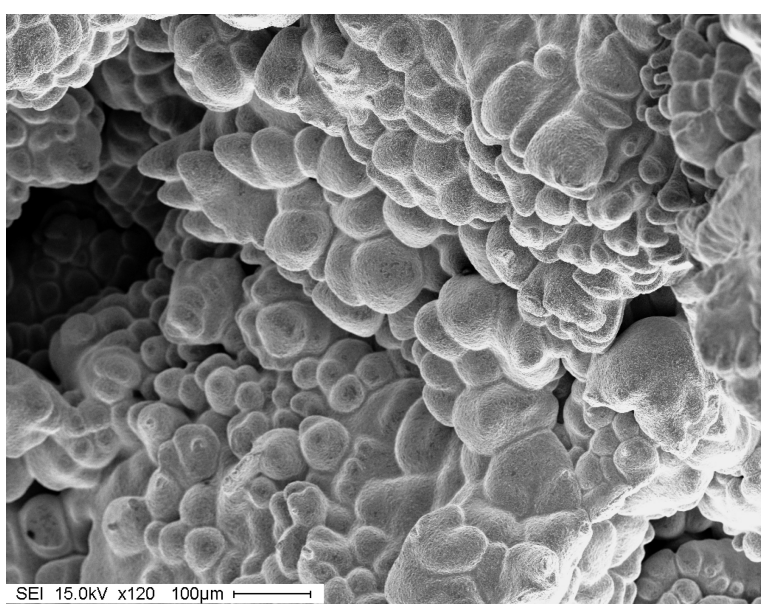

Fig. 6. Dendritic structure of the $\mathrm{Nb}-\mathrm{Ti}-\mathrm{B}$ steel fractured at the incipient melting point in the continuous heating tensile experiment.

The fracture surface of the $\mathrm{Nb}-\mathrm{Ti}-\mathrm{B}$ steel subjected to the continuous heating tensile experiment is shown in Fig. 6. The dendritic structure explains that the specimen was partially melted at $\delta$-ferrite grain boundaries toward grain interiors. Therefore, the strength of material decreased abruptly to almost zero since there was no resistance to the tension from the melting material. This corresponds with the incipient melting temperature in Fig. 2. When the specimen was cooled a few degrees below the incipient melting temperature, the liquid solidified into a dendritic structure. The fracture surface obtained for the $\mathrm{Nb}-\mathrm{Ti}$ steel at its incipient melting temperature revealed a similar structure.

Figure 7 demonstrates fracture aspects of the steels that were subjected to their respective thermal schedules alone. Figure 7(a) suggests that the fracture was primarily the result of a ductile failure with some brittle characteristics. The brittleness is basically characterized with intergranular facets, i.e. grain boundary surface. There are also some voids and cavities at grain interfaces. However, no precipitates or inclusions were located inside the voids. The $\mathrm{Nb}-\mathrm{Ti}$ steel, Fig. 7(b), displays larger cavities suggesting more extreme grain boundary separation.

The failure mode substantially changed to mostly intergranular when deformation was incorporated with solidifi- 

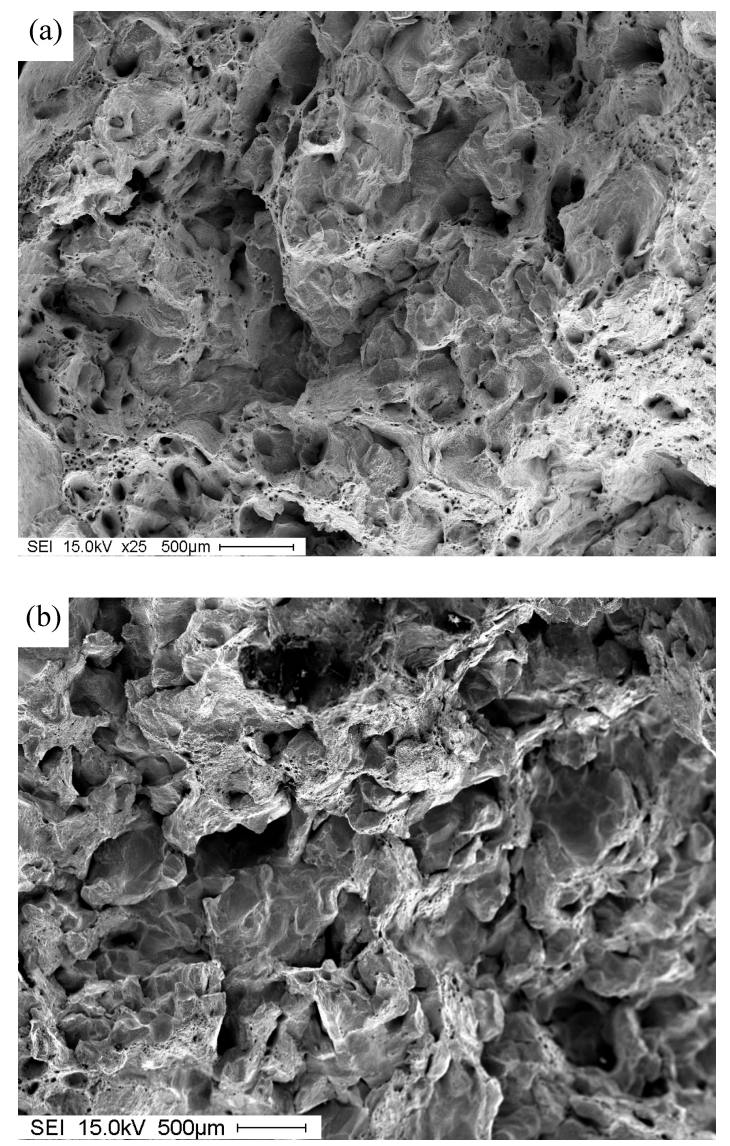

Fig. 7. (a) The $\mathrm{Nb}-\mathrm{Ti}-\mathrm{B}$ steel and (b) the $\mathrm{Nb}-\mathrm{Ti}$ steel subjected to the thermal schedules and fractured at the straightening stage.

cation. Fracture features shown in Fig. 8 distinctly demonstrate this fact. Both Figs. 8(a) and 8(b) exhibit large as cast grains and a very conspicuous grain boundary separation. It seems that, in Fig. 8(a), grains were also somewhat elongated toward the tensile direction and the facet separation planes are parallel to this direction. Nevertheless, despite the appearance of longitudinal planes that are facetted, there is evidence of some plastic deformation on transverse planes as revealed grain boundary cavities, Fig. 8(a). This indicates that the rupture was associated with void nucleation and coalescence at grain boundaries. On the contrary, the specimen subjected to tension during solidification, Fig. 8 (b), was not strong enough to withstand adequate deformation for grains to be somewhat elongated and they remained equiaxed under the tension at the straightening stage. Therefore, longitudinal grain separation is not as prevalent as it is in Fig. 8(a) and they are mainly attached together. Even though grain boundaries look facetted in the fracture picture, they have a fibrous appearance if observed in the FEGSEM, Fig. 9(a). In addition, fracture of the specimen revealed some wavy features at grain boundaries, as shown in Fig. 9(b), which can be attributed to the fracture of a liquid film, most probably occurred during the compression in the 'liquid+solid' region.

The situation became even worse, i.e. $\sim 0 \%$ RA, when $5 \%$ compression was just limited in the two-phase 'liquid+solid' region, Fig. 10. As Fig. 10(a) illustrates, the failure is substantially intergranular with no evidence of plastic deformation. Also, columnar grains of about $1 \mathrm{~mm}$ long
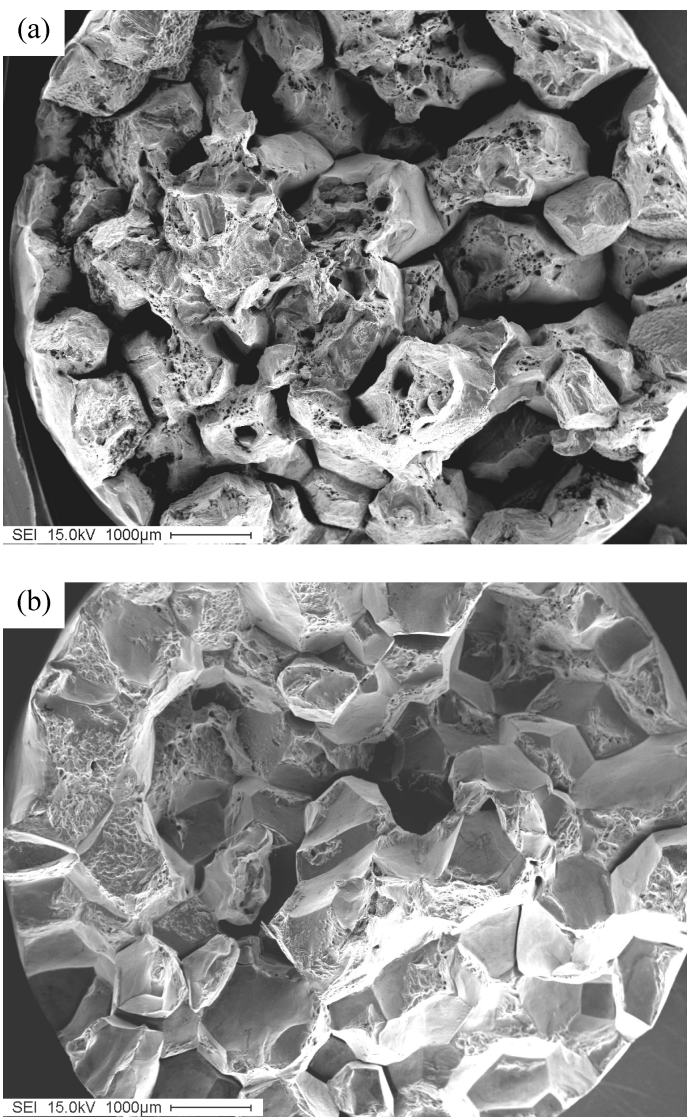

Fig. 8. The $\mathrm{Nb}-\mathrm{Ti}-\mathrm{B}$ steel deformed in (a) compression and (b) tension during solidification and fractured at the straightening stage.
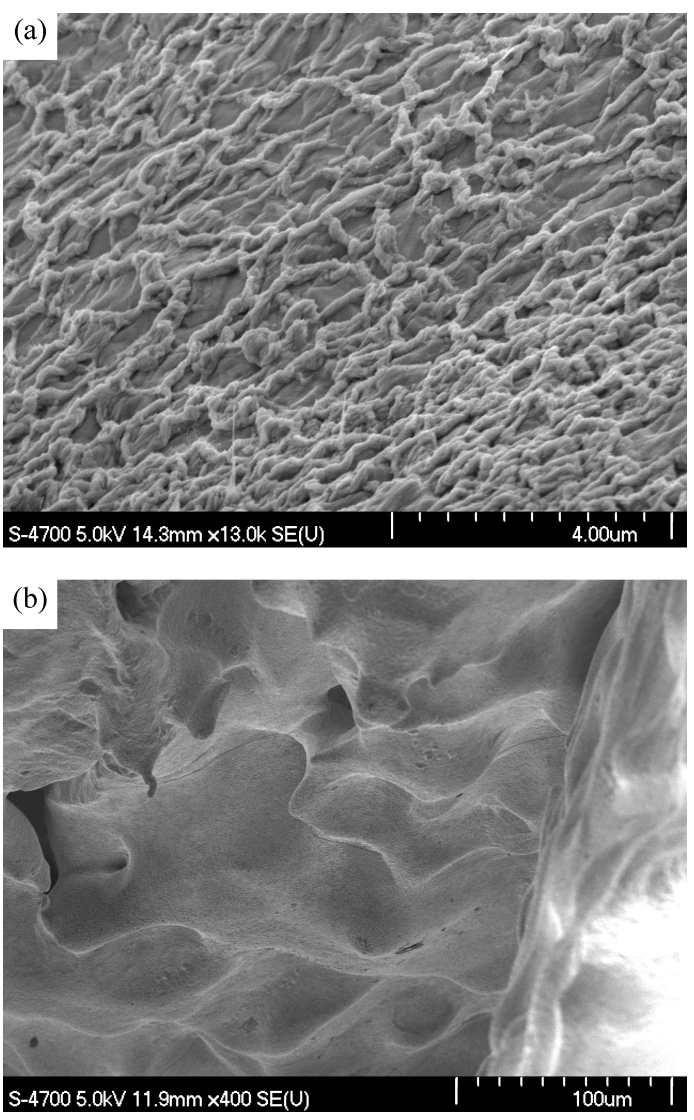

Fig. 9. Grain surface of the $\mathrm{Nb}-\mathrm{Ti}-\mathrm{B}$ steel deformed in compression during solidification and fractured at the straightening stage. 

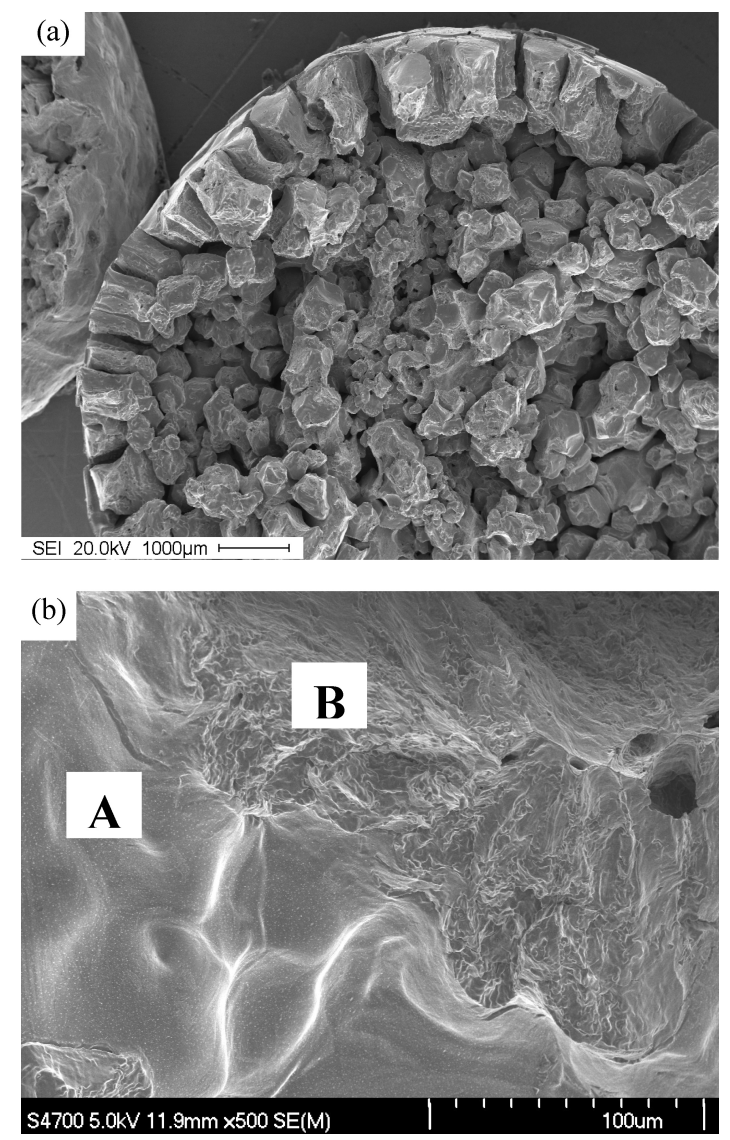
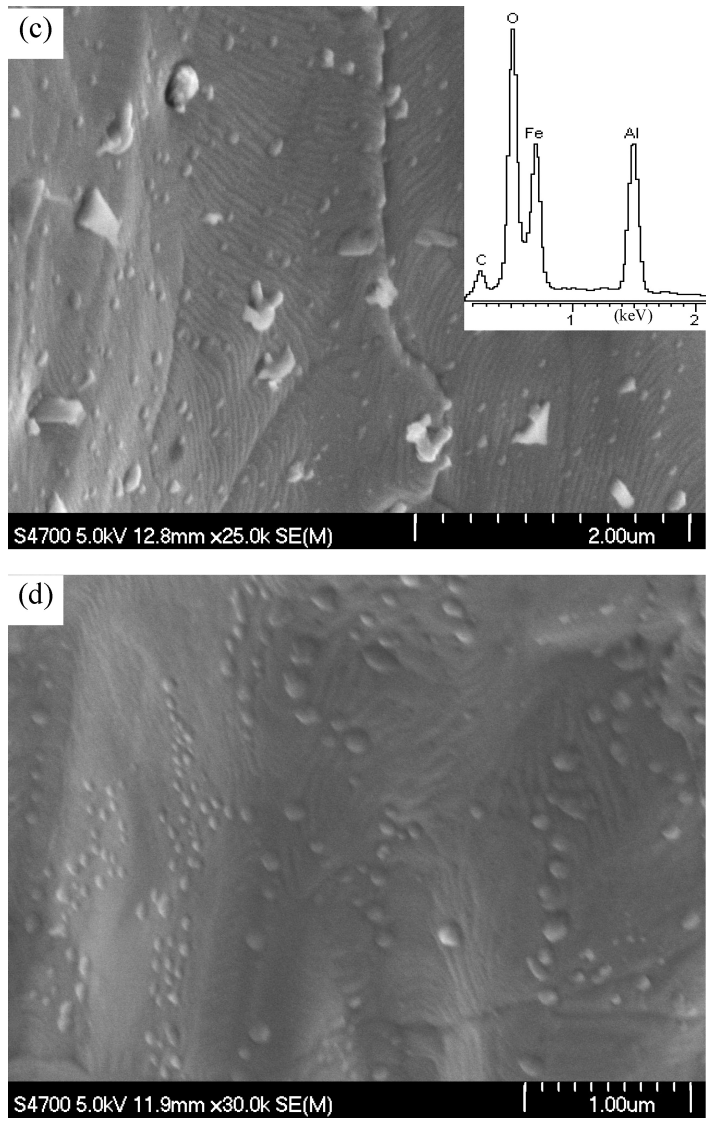

Fig. 10. The $\mathrm{Nb}-\mathrm{Ti}$ steel deformed in compression $(\varepsilon=0.05)$ during solidification and fractured at the straightening stage. Images 'c' and 'd' are magnified regions of A and B in image 'b', respectively ( $0 \% \mathrm{RA})$.

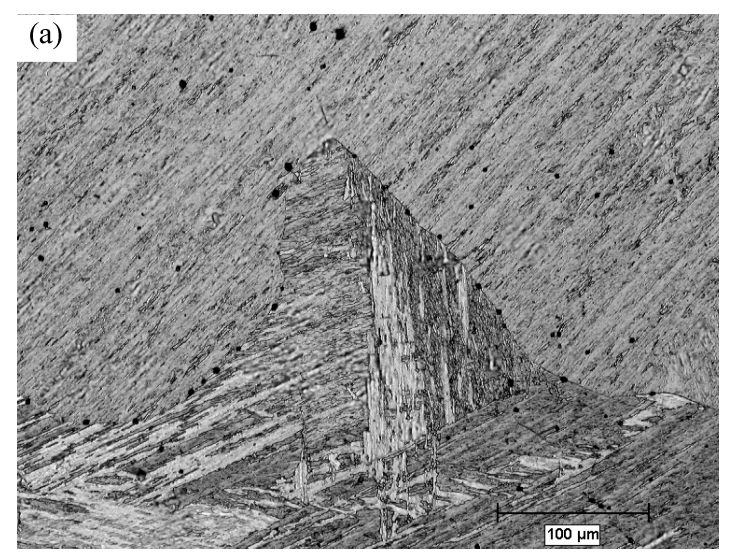

(b)

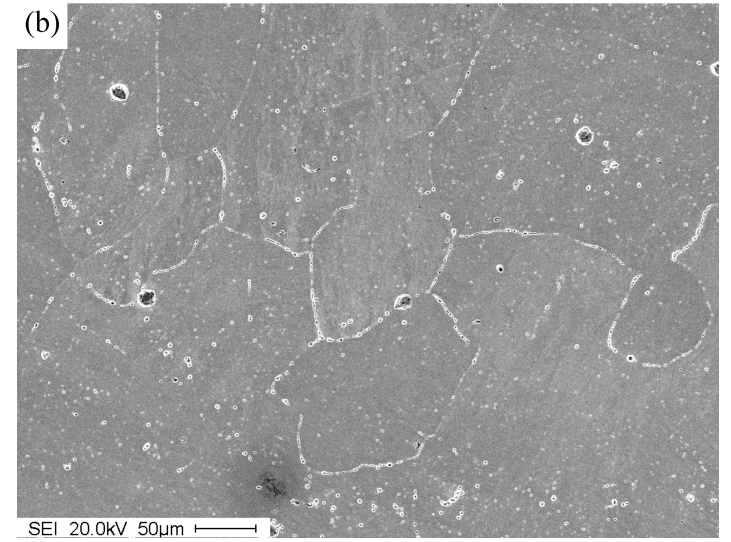

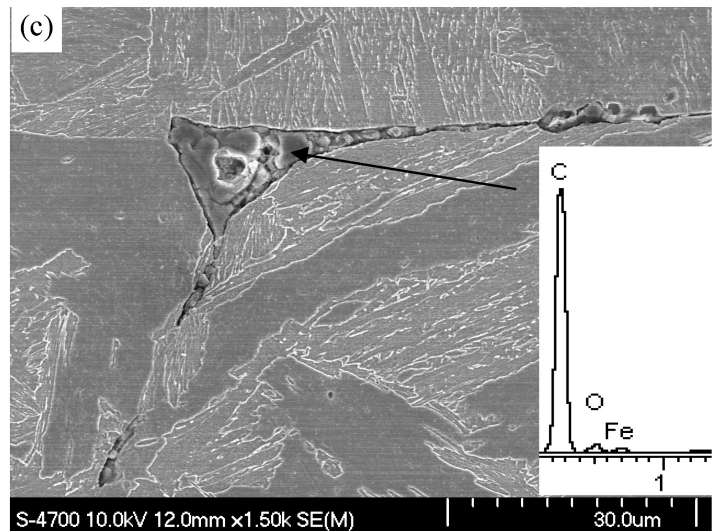

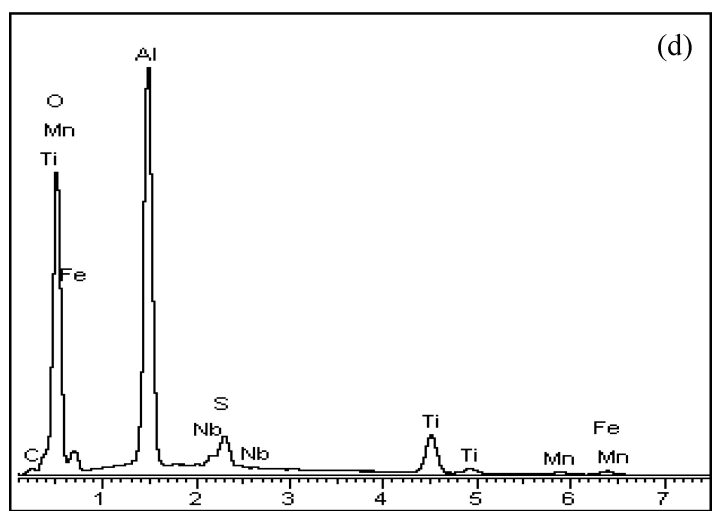

Fig. 11. Microstructures of the Nb-Ti-B steel deformed in (a) compression and (b) tension during solidification and fractured at the straightening stage. (c) is an EDS analysis at a grain boundary: (d) is a typical EDS analysis of particles at grain boundaries shown in (a) and (b). 
formed peripherally during solidification are noticeable. The grain surfaces are composed of two distinct relatively smooth and rough regions as designated by $\mathrm{A}$ and $\mathrm{B}$, respectively, in Fig. 10(b). Examination in the FEGSEM revealed particles of irregular shape in size of 100 to $400 \mathrm{~nm}$ that are dispersed on the smooth region, Fig. 10(c). Characteristic X-ray analysis of these particles identified $\mathrm{Fe}, \mathrm{Al}$, and $\mathrm{O}$ as major elements. Assuming that the $\mathrm{Fe}$ signal in the spectrum has come from the iron matrix, these particles can be identified as $\mathrm{Al}_{2} \mathrm{O}_{3}$. Nevertheless, no precipitates were found on the rough region, Fig. 10(d). This region displays a kind of shear-like appearance at grain boundaries, especially with cavities on grain surface, as presented in Fig. 10(b).

The quenched microstructure at the straightening stage, just before the tensile strain to fracture, is shown in Fig. 11. Figures 11(a) and 11(b) show that grain boundaries are decorated with particles and voids after both compression and tension applied during solidification. Also, a high concentration of carbon was found at the grain boundary that can be attributed to carbon segregation during solidification, Fig. 11(c). Such segregation has certainly created a discontinuity at the grain boundary. EDS microanalysis of the grain boundary particles, Fig. 11(d), indicates that they are mainly manganese sulfide ( $\mathrm{MnS})$ and aluminum oxide $\left(\mathrm{Al}_{2} \mathrm{O}_{3}\right)$. The presence of $\mathrm{Ti}$ and $\mathrm{Nb}$ in the spectrum suggests that the nitride and/or carbide of these elements might have co-precipitated with $\mathrm{MnS}$ and/or $\mathrm{Al}_{2} \mathrm{O}_{3}$ or the carbide and nitride have nucleated on the sulfide and oxide. Moreover, Fig. 12 illustrates that the microstructure con-
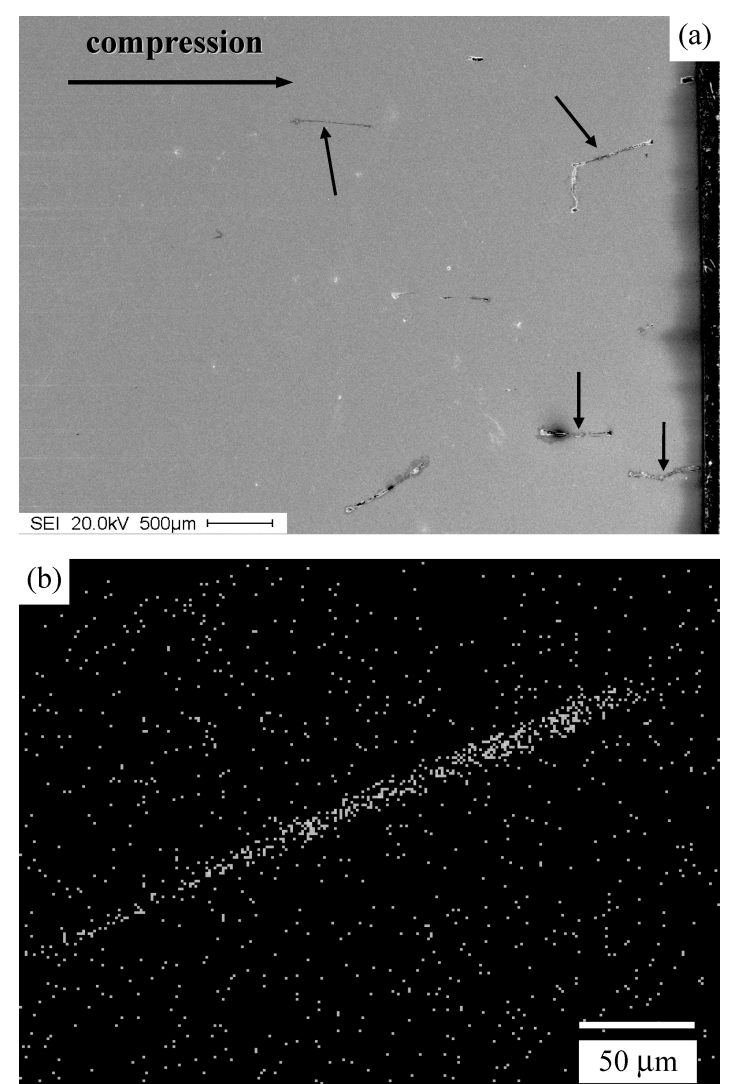

Fig. 12. (a) Cracks, identified by arrows, on the longitudinal cross section of the Nb-Ti-B steel deformed in compression during solidification. (b) is a carbon X-ray map of a crack shown in (a). tains microcracks in the vicinity of the gauge length. As can be seen, these cracks are oriented along the direction of compression imposed during solidification. It was determined that carbon has segregated within these cracks, Fig. 12(b).

The external surface of the specimen explained in Fig. 10 is shown in Fig. 13. Figure 13(a) illustrates a very explicit
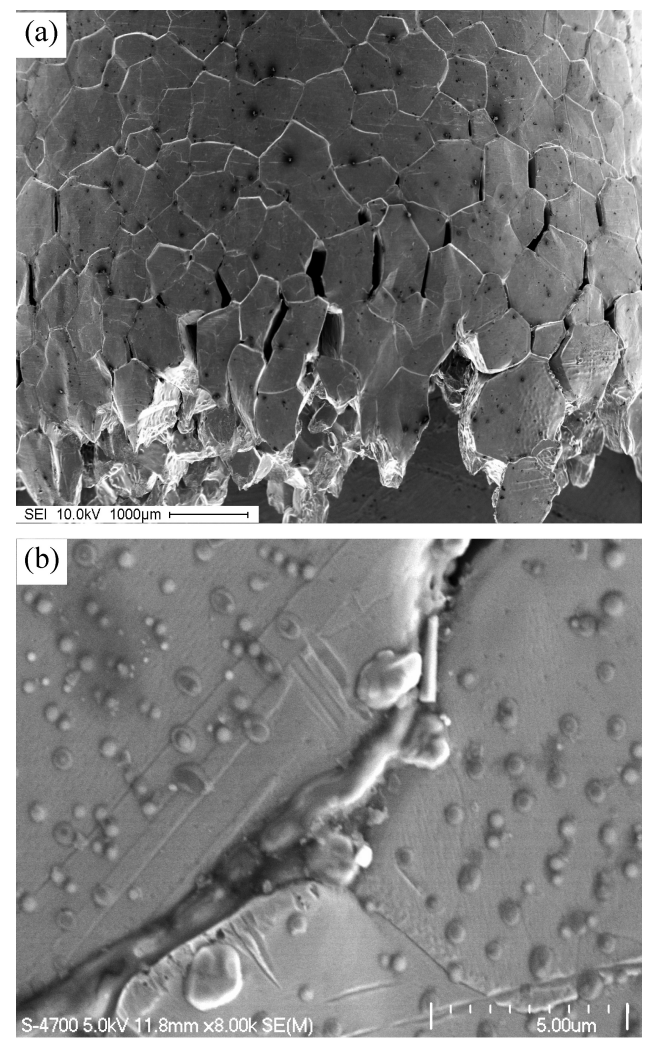

(c)
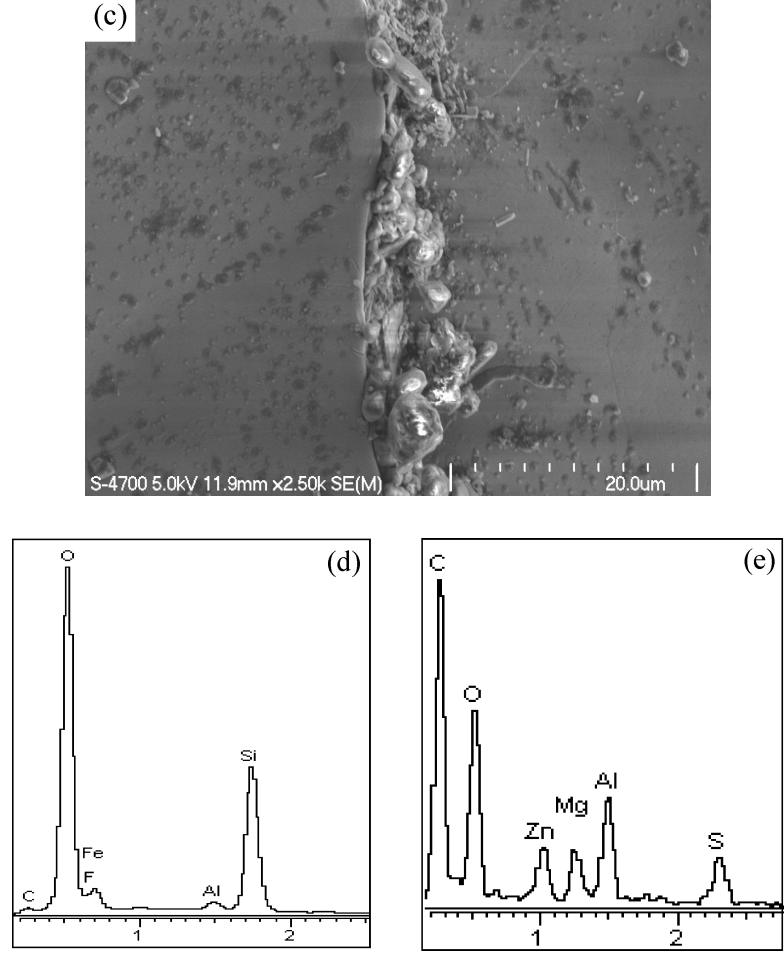

Fig. 13. (a) Outer surface of the Nb-Ti steel shown in Fig. 10. (b) and (c) materials entrapped at grain boundaries, observed in the FEGSEM. (e) and (f) EDS analyses of grain boundary materials shown in (b) and (c), respectively. 
intergranular failure as grain boundaries are clearly delineated on the surface. Looking closely at the surface, two distinct characteristics at grain boundaries can be identified. Figure 13(b) exhibits a liquid-like film, which seems pushed out intergranularly. Squeezed-out inclusions are the second characteristic that occurred on the surface during the compression, Fig. 13(c). EDS analyses of these two characteristics are shown in Figs. 13(d) and 13(e). As can be seen, the liquid-like film at grain boundaries is highly concentrated of $\mathrm{Si}$ and the grain boundary inclusions are composed of $\mathrm{Al}$ and some impurity elements.

\section{Discussion}

Comparing the results of hot ductility evaluation in Table 2 , it is evident that deformation incorporated with solidification is detrimental to the hot ductility and this is independent of the deformation mode. As well, the detrimental effect is independent of composition since the hot ductility has been lessened in both the $\mathrm{Nb}-\mathrm{Ti}$ and the $\mathrm{Nb}-\mathrm{Ti}-\mathrm{B}$ steels.

With regard to tension during solidification, such deformation could prevent solidification cavities from being closed up, and generate cracks and discontinuities in the very weak mushy region (where liquid and solid coexist). Therefore, the solidified structure contains cracks and voids, which are destructive to the hot ductility. On the other hand, at this stage, compression during solidification could help in closing up and healing any cavities that were forming during solidification, i.e. solidification shrinkages. However, compression was also found to be detrimental, but not to the same extent as tension. Considering this, it seems that small voids and discontinuities generated solely by solidification appear to have little influence on the hot ductility.

The fracture characteristics shown in Fig. 8 clearly illustrate that, for both modes of deformation applied during solidification, the failure developed principally through grain boundary separation with facet surfaces, as opposed to mostly sheared surfaces exhibited in Fig. 7(a), where the $\mathrm{Nb}-\mathrm{Ti}-\mathrm{B}$ steel had been subjected to the thermal schedule alone. Therefore, it appears that interactions between the deformation during solidification and other phenomena taking place in the mushy zone resulted in weakness of grain boundaries.

One possibility is that the deformation affected segregation characteristics and this led to the loss of hot ductility at the straightening stage. Segregation or enrichment of solutes and alloying elements is the most important phenomenon occurring during the solidification of steel. Using the Scheil equations, microsegregation resulted from solute rejection during dendritic freezing in steel can be considered as follows ${ }^{12,13)}$;

for interstitilas: $\quad C_{1}=\frac{C_{0}}{k+(1-k) g}$

for substitutionals: $\quad C_{1}=C_{0} g^{k-1}$

where $g$ is volume fraction of remaining liquid in any given volume element of the solidifying mass, $C_{0}$ initial solute concentration at $g=1, C_{1}$ solute concentration in the en-

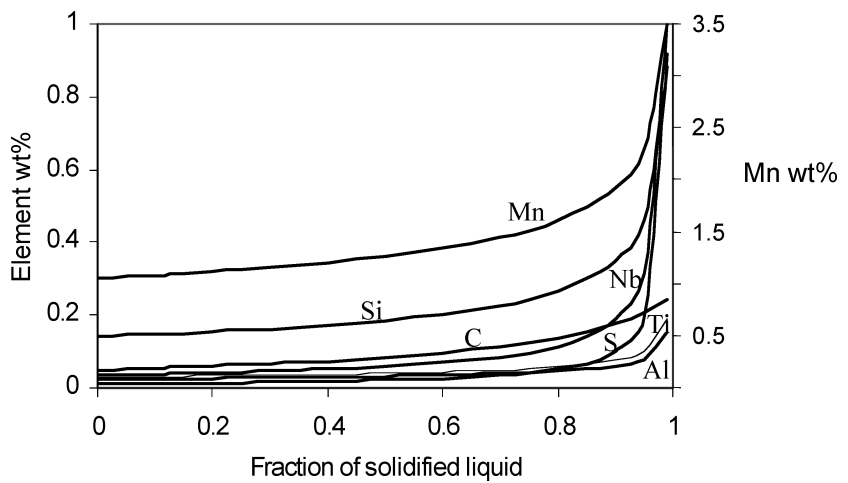

Fig. 14. Interdendritic solute enrichment in the $\mathrm{Nb}-\mathrm{Ti}$ steel during solidification, if there is no reaction between elements during solidification.

riched liquid, and $k$ is solid/liquid equilibrium solute distribution ratio. Regarding $k$ values found in ref. 13), segregation profiles for the $\mathrm{Nb}$-Ti steel during solidification can be determined as shown in Fig. 14. Similar profiles are obtained for the $\mathrm{Nb}-\mathrm{Ti}-\mathrm{B}$ steel. However, the intensity of carbon segregation is less in the latter.

When solute concentrations in the interdendritic liquid become sufficiently high, reactions may occur between the solutes resulting in the formation of oxide, silicate, oxysulphide inclusions, and gas bubbles. An important reaction in the impurity enriched interdendritic liquid is the precipitation of $\mathrm{MnS}$ inclusions. In the vicinity of the liquidus temperature, the solid $\mathrm{MnS}$ solubility product $[\% \mathrm{Mn}][\% \mathrm{~S}]$ is about $0.92 .{ }^{13)}$ Then, as $\mathrm{Mn}$ and $\mathrm{S}$ profiles in Fig. 14 suggest, $\mathrm{MnS}$ obviously precipitates in the interdendritic liquid, especially during the later stages of solidification. In the case of rapid rates of solidification, as in the thermal schedule, the local equilibrium reaction may not prevail and some liquid ' $\mathrm{FeS}$ ' may precipitate in the last liquid to freeze. This can happen even though the ratio of $\mathrm{Mn} / \mathrm{S}$ in the steel is greater than the critical value for $\mathrm{MnS}$ to precipitate. ${ }^{13)}$ Such reaction has been shown to deteriorate the hot ductility of steel. ${ }^{1)}$ Some evidence for a combination of FeS and $\mathrm{MnS}$ on fracture surfaces have been already reported and a mechanism that requires the precipitation of $\mathrm{FeS}$ in lieu of $\mathrm{MnS}$ during cooling from high temperatures has been proposed. ${ }^{1)}$

$\mathrm{Al}$ and $\mathrm{Si}$ both decrease the liquidus temperature in steel. The rate of this reduction is 2.5 and $14{ }^{\circ} \mathrm{C} / \mathrm{wt} \%$ for $\mathrm{Al}$ and $\mathrm{Si}$, respectively. In addition, $\mathrm{Si}$ reduces the surface tension of iron liquid by $30 \mathrm{mN} \mathrm{m}^{-1} / \mathrm{wt}^{2}$. $^{13)}$ Certainly, these effects are more intense in the later percentages of liquid being solidified since it is highly segregated of these elements.

Based on this information, the effect of deformation during solidification is explained as follows.

In the first cooling segment of the thermal schedule, solidification starts with formation of dendrites and columnar grains growing toward the center of specimen, Fig. 10(a). Hence, the remaining liquid is confined inside a solidified shell as shown schematically in Fig. 15(a). As the solidification proceeds inside the shell, the liquid between grains becomes more and more enriched of alloying elements (Fig. 14). The segregated liquid is shown in Fig. 15(a) at both horizontally and vertically growing grain boundaries. The segregated liquid is also more fluid mostly because of 


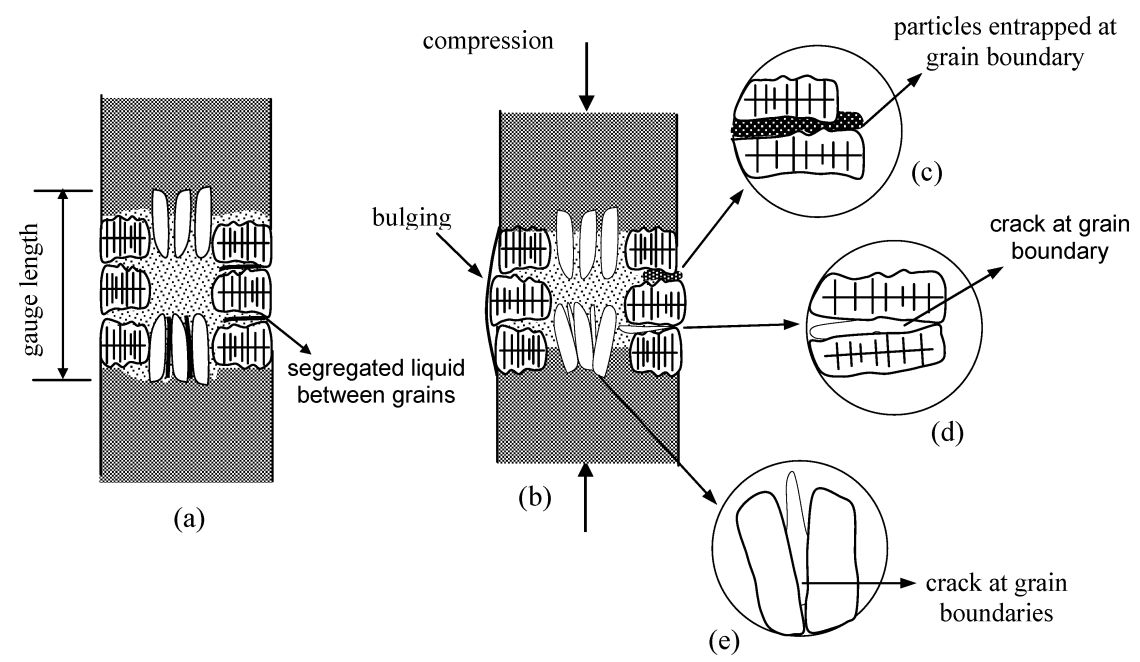

Fig. 15. Mechanism of crack formation and loss of grain boundary strength due to compression during solidification.

segregated $\mathrm{Si}$. This was confirmed by EDS analysis of the liquid solidified between grains, where a high concentration of Si was detected, Figs. 13(b) and 13(d). On the other hand, according to the $\mathrm{Fe}-\mathrm{Si}$ equilibrium phase diagram, ${ }^{14)}$ and the relative amount of $\mathrm{Si}$ to $\mathrm{Fe}, \mathrm{a} \mathrm{Fe}-\mathrm{Si}$ eutectic compound is likely to form at $1200^{\circ} \mathrm{C}$. Therefore, some liquid at grain boundaries might have a delayed solidification till $1200^{\circ} \mathrm{C}$.

When such a solidifying structure is subjected to a compressive deformation longitudinally, the solidified shell bulges out horizontally owing to the internal hydrostatic pressure from the liquid to the solidified shell, as shown schematically in Fig. 15(b). Simultaneously, the liquid is extruded into grain interspaces and transfers and accumulates particles and inclusions at grain boundaries. When the solidification is completed, the accumulated particles remain at grain boundaries leading to severely weakened grain boundaries. This is illustrated in Figs. 13(c) and 15(c). Here, the accumulation of particles plays the main role in weakening grain boundaries and particles distribution due to equilibrium solidification does not necessarily lead to any considerable loss of hot ductility. Also, in addition to particles, the highly segregated liquid is compressed and sheared between horizontal grains leading to grain boundary cracks upon completion of solidification, Fig. 15(d). A typical example of this is shown in Fig. 11(c) where high segregation of carbon was determined inside cracks at grain boundaries. Furthermore, during compression, the liquid is pushed between grains growing longitudinally and, hence, inclining them horizontally toward the bulging direction of the gauge length, Fig. 15(b). This, at later stages of solidification, results in discontinuities at the grain boundary segregated liquid and, consequently, intergranular cracks in the resultant solid. This is illustrated in Figs. 9(b), 12(a) and schematically in Fig. 15(e). Note that such cracking occurs because solid and liquid are adjacent to each other, and this is the liquid that endures the most deformation and is sheared and cracked during solidification. In this respect, low melting point phases such as FeS and FeSi can be effective. Grain boundary separation resulting in grain surfaces with liquid-like appearances, demonstrated in Fig. 10, can be attributed to these phenomena.

On the other hand, the movement of liquid along its in- terface with the solid could make diffusion difficult through the solidification front. This can lead to two adverse consequences. Firstly, the solute concentration in the liquid will be more severe than when the liquid is stationary. Therefore, all the deleterious effects due to segregation are more intense. Itoyama et al. ${ }^{4)}$ investigated the effect of oscillations during solidification in the continuous casting and proposed that the pressure change can alter the amount of enriched molten steel in interdendritic regions, although no specific mechanism for the interaction between deformation and segregation was offered. Salvadori et al. ${ }^{15)}$ studied the effect of liquid agitation (stirring) on the segregation ratio and found that the stirring enhances intergranular segregation during the steel solidification. However, the exact interaction between deformation/agitation in liquid and segregation patterns has not yet been well documented.

The second potential defect, because of the moving liquid, is that a strong bond between current and new solids, at the solidification front, could be difficult to be established, especially during later stages of solidification. In this respect, the final consequence is a weakened grain boundary.

A noticeable aspect regarding the grain surface is a fibrous structure covering the grain surface as shown in Fig. 9(a). This structure was observed in almost all specimens subjected to the thermal schedules alone and the thermal schedules incorporated with deformation during solidification. Hence, it would appear that deformation was not necessary to form such fibers. Meanwhile, no clear explanation can be suggested for such a grain boundary structure. It may be a usual as cast grain boundary structure observed in a very high resolution electron microscope. As well, it may be a second phase solidified/formed on the grain surface during solidification and/or cooling. ${ }^{16,17)}$ However, only iron, carbon, and oxygen were detected in the EDS analysis of these fibers. As the specimens were air cooled or quenched in water after the fracture, the presence of oxygen is rather unlikely to be ascribed to a grain boundary phase formed before the fracture.

Two different regions on grain surfaces in Fig. 10(b) suggest that there must have been two different modes that contributed to the final fracture. The facet region, designated by A (Fig. 10(c)), contains irregular shaped particles of $\mathrm{Al}_{2} \mathrm{O}_{3}$. Suzuki et al. ${ }^{18)}$ detected similar precipitates on 
austenite grain surfaces in a plain carbon steel subjected to in situ melting and fractured intergranularly at temperature range of $900-1200^{\circ} \mathrm{C}$. They also reported corresponding grain boundary dimples associated with the fracture. However, in the current work, it seems that grain boundaries were too weak to withstand the load needed for void nucleation and growth at the precipitates and grain boundaries separated before formation of voids. This is also consistent with the values obtained for the reduction in area for this specimen and those by Suzuki et al., being 0 and $\sim 20 \%$, respectively. As explained before, the liquid movement during solidification can be considered as a cause for this severe grain boundary weakness. On the contrary, no precipitates were found on the rough region, designated by B, Fig. 10(d). Shear-like appearance and cavities in this region, Fig. 10(b) imply a stronger characteristic for the grain boundary, as opposed to region A. Therefore, it can be concluded that the failure, at grain boundaries, initiated at region $\mathrm{A}$ and extended to region $\mathrm{B}$. In other words, region $\mathrm{A}$ behaved as a grain boundary crack that propagated through region $\mathrm{B}$ leading to an early rupture.

The presence of segregated low melting point phase entrapped between dendrites, because of deformation, was also observed and explained by other investigators. Harada et $a l .{ }^{19)}$ studied the effect of bending deformation in the mould in the continuous casting process and proposed that the deformation can cause the segregated liquid to be entrapped between dendrites that leads to cracking during subsequent deformation processes. Barber and Perkins ${ }^{20)}$ proposed a finite element model to approximate the strains resulted from bulging, roll misalignment, and bending of the semisolid strand during continuous casting. They concluded that, in order to prevent internal cracking, casting machines should be designed and operated such that the total strain at each position in the strand is minimized. More recently, Han et al. ${ }^{21)}$ developed mathematical models for strain analysis and microsegregation during continuous casting of slab. They showed that the interaction between deformation and segregation during solidification leads to internal cracking of slabs.

As for the detrimental effect of tensile deformation during solidification, the mechanism of hot ductility deterioration is much less complicated. Tension during solidification can readily create cracks at the remaining liquid. Here, even though segregation can interact with tension, its interaction may not seem as much necessary as it occurs during compression in order to produce a detrimental result since the tension is deleterious enough by itself to decrease the hot ductility markedly.

The intensity of such destructive effect of deformation during solidification depends on both the strain rate and the temperature at which the deformation starts. It was found that the higher the strain rate is, the more deleterious the deformation is. Also, deformations started at higher temperatures during solidification appeared more detrimental than those started at lower temperatures but still within the solidification region.

The mechanism of cracking discussed above explains that, during solidification, the detrimental effect of compression suppresses its beneficial effect owing to the clo- sure of solidification cavities. As for the relevance to the continuous casting process, the bending deformation of the solidifying shell creates a situation reminiscent the bulging effect of gauge length explained above where a segregated liquid is entrapped between grains. Therefore, it appears that incorporating deformation during solidification is one step forward in the evolution of hot ductility evaluation in laboratory, where it is attempted to simulate the industry parameters to the most possible extent. This may be considered as a necessity if laboratory findings are to be more directly applied to the industry.

\section{Conclusions}

It appeared that any deformation during solidification of steel can lead to loss of hot ductility. It was shown that deformation can interact with segregation taking place during solidification and this can result in grain boundary weakness and cracking. However, segregation by itself is not as much harmful to the hot ductility since the $\mathrm{Nb}-\mathrm{Ti}-\mathrm{B}$ steel showed good ductility when it was subjected to the thermal schedule alone.

\section{Acknowledgement}

The authors gratefully acknowledge the financial assistance of the Canadian Steel Research Association and the Natural Sciences and Engineering Research Council of Canada.

\section{REFERENCES}

1) W. T. Lankford: Metall. Trans., 3 (1972), No. 6, 1331.

2) J. K. Brimacombe and K. Sorimachi: Metall. Trans. B, 8B (1977), No. 9,489

3) B. Mintz, S. Yue and J. J. Jonas: Int. Mater. Rev., 36 (1991), No. 5, 187.

4) S. Itoyama, H. Tozawa, T. Mochida, K. Kurokawa, T. Matsukawa and K. Sorimachi: ISIJ Int., 38 (1998), No. 5, 461.

5) O. J. Ilegbusi and J. Szekely: ISIJ Int., 29 (1989), No. 12, 1031.

6) I. Miyoshino, E. Takeuchi, H. Yano, J. Sakane, T. Saeki and H. Kajioka: ISIJ Int., 29 (1989), No. 12, 1040.

7) J. W. Evans, B. Q. Li, and D. P. Cook: ISIJ Int., 29 (1989), No. 12, 1048.

8) N. Genma, T. Soejoima, T. Saito, M. Kimura, Y. Kaihara, H. Fukumoto and K. Ayata: ISIJ Int., 29 (1989), No. 12, 1056.

9) B. Mintz: ISIJ Int., 39 (1999), No. 9, 833.

10) S. Akhlaghi: Ph.D. thesis, McGill University, (2000).

11) A. M. Elwazri: Master's thesis, McGill University, (1998).

12) C. M. Flemings: Solidification Processing, McGraw-Hill, Columbus, $\mathrm{OH},(1974), 34$.

13) E. T. Turkdogan: Fundamentals of Steelmaking, The University Press, Cambridge, (1996), 297.

14) ASM Metals Handbook, 8th Ed., Vol. 8, Metallography, Structures and Phase Diagrams, ASM, Metals Park, OH, (1973), 306.

15) D. Salvadori, M. Bobadilla, G. Lesoult, D. Benoit and B. Debiesme: Rev. Metall., Cah. Inf. Tech., 90 (1993), No. 2, 211.

16) G. F. Vander Voort: Private Communications, (2003).

17) ASM Failure Analysis and Testing Discussion Group: Private Communications, (2003).

18) H. G. Suzuki, S. Nishimura and S. Yamaguchi: Trans. Iron Steel Inst. Jpn., 22 (1982), 48.

19) S. Harada, S. Tanaka, H. Misumi, S. Mizoguchi and H. Horiguchi: ISIJ Int., 30 (1990), No. 4, 310

20) B. Barber and A. Perkins: Ironmaking Steelmaking, 16 (1989), No. 6, 406.

21) Z. Han, K. Cai and B. Liu: ISIJ Int., 41 (2001), No. 12, 1473. 